\title{
Superior Properties of Ultra-fine-grained Steels
}

J. I. Leinonen

\begin{abstract}
A description of the improved mechanical properties obtained in ultra-fine-grained steels up to now will be presented in this paper, and some potential applications of these new generation steels will be described. In addition, the principle and implementation of a novel hot rolling process developed by the author will be introduced. This novel Thermomechanical Nonrecrystallisation Control Process (TNCP) has been shown to give an ultra-fine ferrite (uff) structure with grain sizes of 2 to $3 \mu \mathrm{m}$ in various test steels, thus resulting in super-toughness. Charpy V impact test results suggest that some of these steels could still be tough at temperatures lower than $-100{ }^{\circ} \mathrm{C}$. This novel process, $T N C P$, is one potential candidate for the commercial production of superior ultra-fine-grained steels in the future.
\end{abstract}

Keywords: ultra-fine-grained steel, super-toughness, yield strength, fatigue strength, TNCP.

\section{Introduction}

Steel is nowadays a very suitable material for many structural uses because of its low cost, good formability, variable strength with good toughness, and good weldability. Still better steels are required, however, because those available at present do not meet the high standards of this century.

Ultra-fine ferrite (uff) microstructures with grain sizes usually not more than $3 \mu \mathrm{m}(0.003 \mathrm{~mm})$ have been shown to result in superior combinations of mechanical properties, much better than those in the present steels with grain sizes of about 5 to $20 \mu \mathrm{m}$. High strength, excellent impact toughness even at very low temperatures, and very good fatigue strength together with good formability and weldability can be obtained at the same time in an ultra-fine grained steel. Most of the test steels used in numerous investigations worldwide have been produced on a laboratory scale, but a few have been made in commercial plate mills.

Numerous research projects to develop still better structural steels, e.g. "ultra steels" or "super steels", have been commenced all over the world since the mid-1990s, especially in Asia (e.g. Japan, South Korea, China), Australia and Europe. One of the main goals of Japan's enormous national 10-year "ultra steel project", for example, is to achieve a strength level of $800 \mathrm{MPa}$ for unalloyed silicon-manganese steels $[1,2]$. This means that the grainy microstructure of the steel will have to be much finer than at present. The aim of most current projects is to achieve an ultra-fine grain structure, with a grain size usually of not more than $3 \mu \mathrm{m}$ $(0.003 \mathrm{~mm})$, in conventional steels. This is assumed to ensure high strength and very good toughness even at very low temperatures [3]. Novel processes for producing these ultra-fine-grained steels have been developed lately, e.g. in Japan [2], Finland [4, 5] and Australia [6].

A description of the improved mechanical properties obtained in ultra-fine-grained steels up to now will be presented in this paper, and some potential applications of these new generation steels will also be described. In addition, the principle and implementation of a novel hot rolling process, TNCP $[4,5]$, developed by the author will be introduced.

\section{Superior properties of uff steels}

Ultra-fine-grained steels have often been shown to have mechanical properties superior to conventional structural steels with common microstructures. Yield strength and fatigue strength have been shown to increase markedly with reduced grain size, and impact toughness has improved radically. The effect of ferrite grain size on yield strength and impact transition temperature (tough/brittle), extrapolated to ultra-fine grain sizes, is shown in Fig. 1.

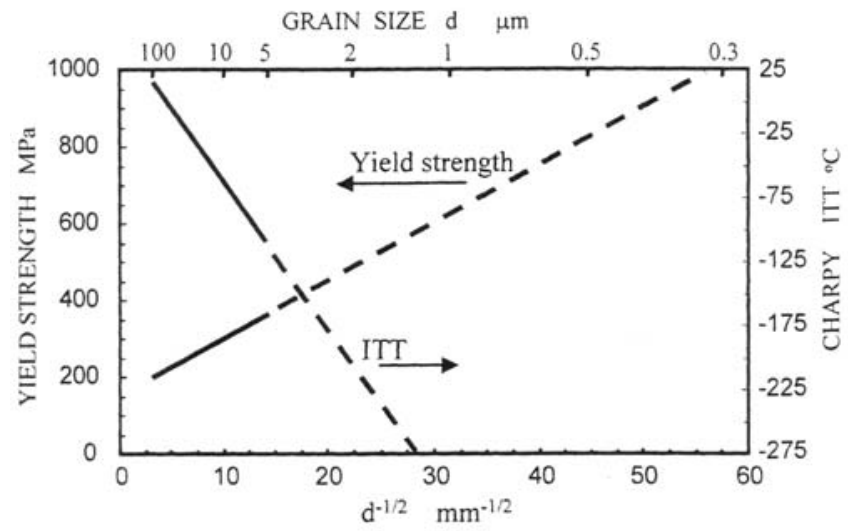

Fig. 1: Dependence of yield strength (YS) and Charpy impact transition temperature (ITT) on ferrite grain size, extrapolated to ultra-fine grain sizes [7]

The main attention in the new research work that arose in the 1990s regarding the benefits of ultra-fine-grained steels was paid to higher yield and tensile strength. One of the main goals of Japan's enormous national 10-year "ultra steel project”, for example, was to achieve a strength level of $800 \mathrm{MPa}$ for unalloyed silicon-manganese steels [1, 2]. This means that the ferrite grain size should be about $0.5 \mu \mathrm{m}$ (Fig. 1). A stronger but lighter steel will contribute to improving the fuel efficiency of automobiles and increasing the thermal efficiency of power generation plants, as well as reducing carbon dioxide emissions [2]. 
It is problematic in practice, however, to use uff steels with $1 \mu \mathrm{m}$ or smaller grain sizes in real structures, because these would involve a substantial reduction in uniform elongation and very little work hardening occurs [8]. Therefore the ferrite grain size should preferably be 2 to $3 \mu \mathrm{m}$ or a little more, but this in turn would result in lower strength than a grain size of $1 \mu \mathrm{m}$. This drawback can be mainly eliminated by producing low carbon steels with bainitic or even martensitic microstructures, having higher original strength. In this case maximum yield strengths of about 1000 MPa may be achieved as well as good impact toughness and reasonable weldability [5].

An ultra-fine grain structure has been shown in various steels to result in super-toughness. The impact toughness transition temperatures of these steels have been radically lowered as the grain sizes were reduced from about $10 \mu \mathrm{m}$ to 2 to $3 \mu \mathrm{m}$ by TNCP [9]. Their good toughness at very low temperatures means that these steels could very well be called "ultra-arctic", for example, and could be employed in various structures used at very low temperatures, e.g. in arctic regions.

For a low-carbon high-manganese test steel, the absorbed energy in the Charpy $\mathrm{V}$ impact test at $-85^{\circ} \mathrm{C}$, the lowest temperature used, was $96 \mathrm{~J}$ (Fig. 2), a quite exceptional toughness for a structural steel, whereas the corresponding energy before the treatment was only $8 \mathrm{~J}$. Likewise, the difference in transition temperature between the original and treated materials was at least $40{ }^{\circ} \mathrm{C}$. Due to the limited cooling capability, it was not possible to measure the exact transition temperature of the ultra-fine structure, but Fig. 2 suggests that it could be $-100{ }^{\circ} \mathrm{C}$ or even lower.

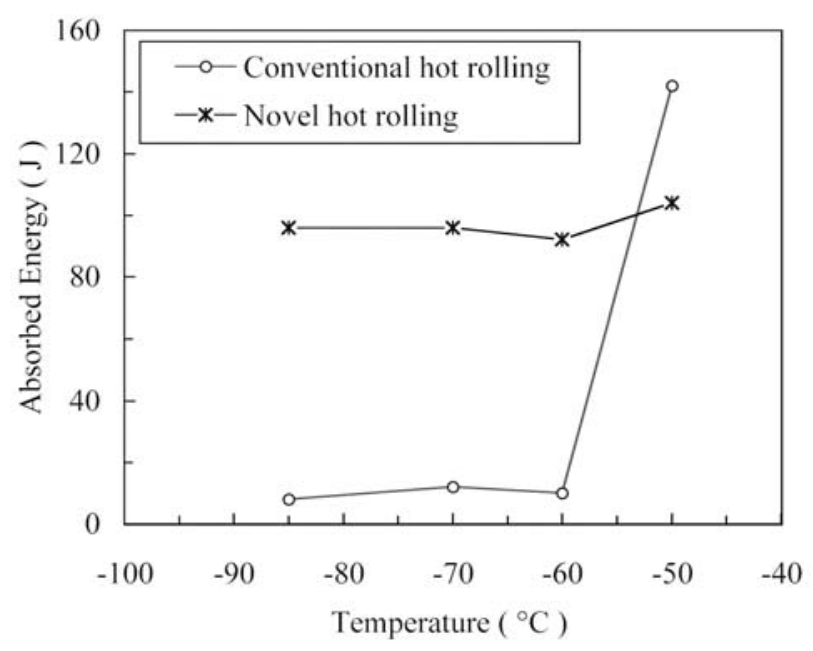

Fig. 2: Absorbed energy in the Charpy $\mathrm{V}$ impact test at various temperatures after conventional hot rolling (o) and after TNCP, a novel hot rolling process (x). Steel A: $0.05 \%$ C, $0.1 \% \mathrm{Si}, 2.5 \% \mathrm{Mn}[9]$

The absorbed impact energy of a medium-carbon steel with a pearlitic-ferritic microstructure is known to be much lower than that of a low-carbon steel with a ferritic or ferritic-pearlitic structure, and its impact toughness transition temperature is fairly high. This poor toughness is mainly due to the high proportion of brittle pearlite in the microstructure. TNCP treatment was shown to improve the impact toughness of a medium-carbon test steel as well, by bringing down the transition temperature sharply, as shown in Fig. 3.

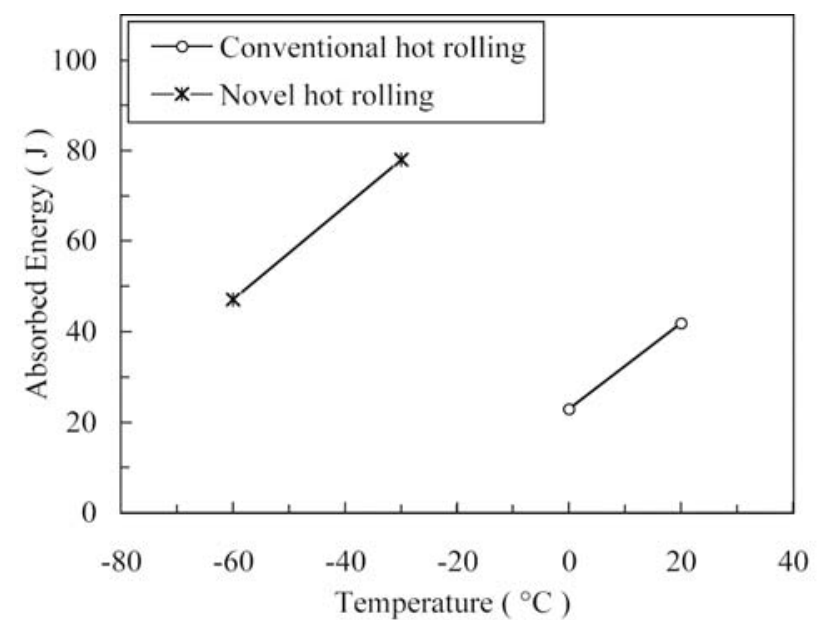

Fig. 3: Absorbed energy in the Charpy $\mathrm{V}$ impact test at various temperatures after conventional hot rolling (o) and after TNCP, a novel hot rolling process (x). Steel B: $0.33 \%$ C, $0.3 \% \mathrm{Si}, 1.2 \% \mathrm{Mn}[9]$

In addition to impact toughness and tensile/yield strength, the fatigue strength of ultra-fine-grained steels has also been found to be superior to that of conventional steels. Test specimens from steel plates with ultra-fine-grained surface layers (SUF) steels exhibited not only higher resistance to fatigue crack initiation and early propagation, but also superior resistance to the propagation of long fatigue cracks [10]. SUF steel plates have already been employed in important members of large structures such as large ships, and the microstructure also has superior fatigue strength in artificial sea water compared with a conventional microstructure [11].

Weight reduction and rigid auto-bodies have been examined extensively in the automotive industry in recent years, from the viewpoints of environmental protection and improvement of collision safety. Some high strength, high elongation tubular products based on ultra-fine grain metallurgy have been developed in order to meet this demand [12].

Advanced steel structures to be manufactured from ultra-fine-grained steels will usually be built by welding. Efficient joining processes with low heat input and narrow width of the heat affected zone (HAZ) have to be used to obtain high-performance welded structures while preserving an ultra-fine microstructure. Laser welding [13] and ultra narrow gap GMA welding [14], for example, have been shown to be adequate processes.

\section{How to produce ultra-fine-grained steels}

Novel processes for producing ultra-fine-grained steels have been developed lately in many places, e.g. in Japan [2], Finland $[4,5]$ and Australia [6].

A detailed description of TNCP, a novel hot rolling process (patent pending) developed by the author (Fig. 1) which results in an ultra-fine grain size [4], is given here.

In TNCP, the steel is first heated to above the $A_{c 3}$ temperature to transform it to a homogeneous austenitic structure. The annealing temperature is often not more than $1000{ }^{\circ} \mathrm{C}$, and in any case not more than $1150^{\circ} \mathrm{C}$, in order to prevent 


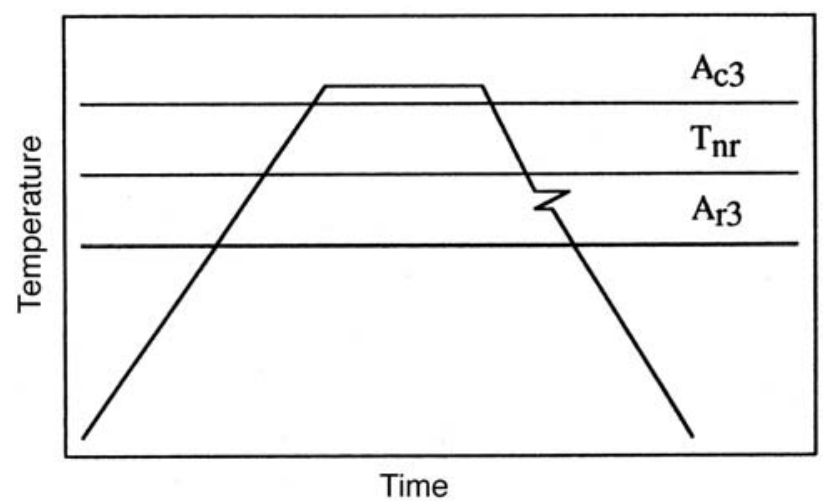

Fig. 4: Schematic time-temperature cycle for producing an ultra-fine grain structure in unalloyed and low-alloy steels by TNCP [9]

excessive growth of the austenite grains. The holding time at that temperature is also constrained, because the austenite grain size before rolling must be less than $20 \mu \mathrm{m}$, and preferably $10 \mu \mathrm{m}$ or less.

The steel is then cooled below the non-recrystallization temperature, $T_{\mathrm{nr}}$, for hot rolling. $T_{\mathrm{nr}}$ depends on the steel composition and is often even above the $\mathrm{A}_{\mathrm{c} 3}$ temperature, but usually not more than $1050{ }^{\circ} \mathrm{C}$. The structure of the steel at this point is austenitic, but no substantial recrystallization of the flat, elongated austenite grains occurs during hot rolling, which can also be continued below the $\mathrm{A}_{\mathrm{r} 3}$ temperature. The total reduction ratio to be achieved in rolling can be rather low, too, but usually not less than 20 to $30 \%$.

After rolling, the steel is cooled below the $\mathrm{A}_{\mathrm{r} 3}$ and $\mathrm{A}_{\mathrm{r} 1}$ temperatures at which the austenite grains will be transformed to various phases. During this cooling and transformation, the prolonged austenite grains change to ultra-fine grains of ferrite, pearlite, etc., depending on the steel composition and cooling rate.

An example of an ultra-fine-grained microstructure produced by TNCP is shown in Fig. 5. The grain size was about $3 \mu \mathrm{m}$. The microalloyed test steel contained $0.08 \%$ carbon, $0.20 \%$ silicon, $1.68 \%$ manganese and $0.04 \%$ niobium, and it was in the conventional hot-rolled state before treatment.

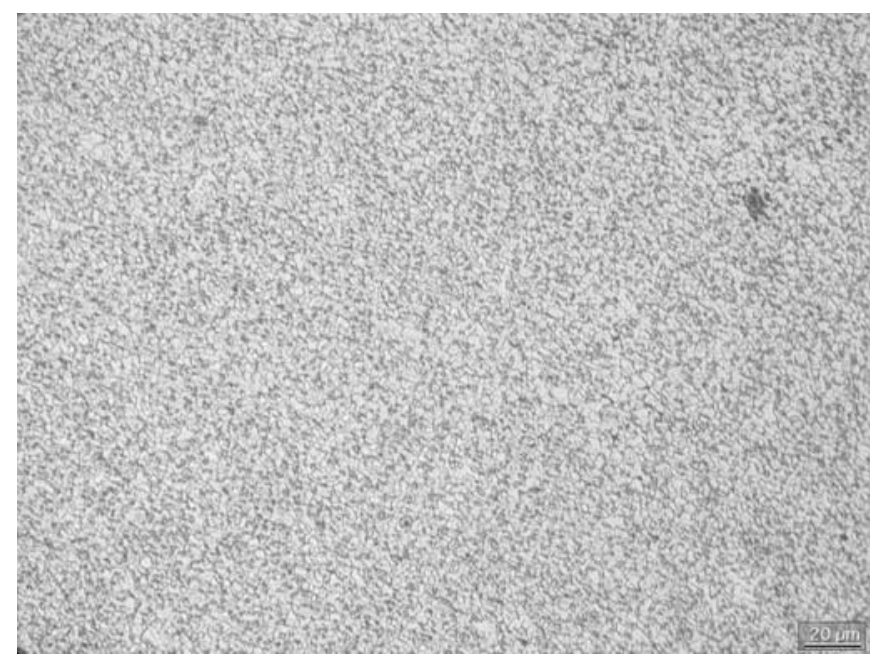

Fig. 5: Microstructure of the ultra-fine-grained TNCP metal
TNCP treatment was carried out according to the principles shown in Fig. 4. Specimens of thickness $8 \mathrm{~mm}$ were heated to the austenite region in an air furnace $\left(900{ }^{\circ} \mathrm{C}\right.$, $30 \mathrm{~min}$ ) and then cooled to $800^{\circ} \mathrm{C}$. Hot rolling with one pass was carried out at this temperature using a laboratory roller with a reduction ratio of $36 \%$. After rolling, the specimens were cooled in a water spray at a rate of about $15^{\circ} \mathrm{C} / \mathrm{s}$.

The Charpy V impact toughness of the TNCP steel was still very good $(114 \mathrm{~J})$ at $-90{ }^{\circ} \mathrm{C}$, the lowest test temperature used. It can be proposed that this steel is still tough at least at $-100{ }^{\circ} \mathrm{C}$.

\section{Conclusions}

The superior mechanical properties obtained in ultra-fine-grained steels and a novel hot rolling process, TNCP, for producing these steels as introduced here, lead to the following conclusions:

1. Tensile/yield strength can be markedly improved by producing steels with ultra-fine grain sizes of usually not more than $3 \mu \mathrm{m}$.

2. High absorbed energies also occur in the Charpy V impact test at very low temperatures, thus showing the super-toughness of these ultra-fine-grained steels.

3. A novel hot rolling process, TNCP, is one potential candidate for the commercial production of ultra-fine-grained steels in the future.

\section{References}

[1] Sato S.: World of Steel (Japan), Vol. 48, (1997), No. 12, p. $14-15$.

[2] Furukawa T.: American Metal Market, Vol. 106, (1997), No. 84.

[3] Hanamura T., Yamashita T., Umezava O., Torizuka S., Nagai K.: Proc. of the Int. Symp. on Ultrafine Grained Steels (ISUGS 2001), Uminonakamichi, Fukuoka, Japan, September 20-22, 2001, p. 228-231.

[4] Leinonen J.: PCT Patent Application PCT/FI00/00902, 2000.

[5] Leinonen J. I.: Advanced Materials \& Processes (USA), Vol. 159, Nov. 2001, p. 31-33.

[6] Hodgson P. D., Hickson M. R., Gibbs R. K.: U.S. Patent 6,027,587. 2000.

[7] Howe A. A.: "Ultrafine grained steels: industrial prospects”. Materials Science and Technology, Vol. 16, November-December 2000, p. 1264-1266.

[8] Priestner R., Ibraheem A. K.: "Ultra-fine grained ferritic steel". Proceedings of the J. J. Jonas Symposium on Thermomechanical Processing of Steel. August 20-23, 2000, Ottawa, Ontario, Canada, p. 351-363.

[9] Leinonen J. I.: "A novel process results in ultra-fine structure and improved properties". Proc. of the $2^{\text {nd }}$ Int. Symp. on High Strength Steel. Verdal, Norway: 23-24 April 2002, 10 p.

[10] Kimura H., Akiniwa Y., Tanaka K., Kondo J., Ishikawa T.: "Microstructural effect on the initiation and propagation behavior of fatigue cracks in ultrafine-grained steel". Proc. of the Int. Symp. on Ultrafine Grained 
Steels (ISUGS 2001), Uminonakamichi, Fukuoka, Japan, September 20-22 2001, p. 248-251.

[11] Fukui T., Yajima H., Ishikawa T., Koseki T.: "Microstructural effect on corrosion fatigue properties in ultrafine grained steel”. Proc. of the Int. Symp. on Ultrafine Grained Steels (ISUGS 2001), Uminonakamichi, Fukuoka (Japan), September 20-22 2001, p. 240-243.

[12] Koyama Y.: "High strength and high elongation tubular products "HISTORY Steel Tube" with good bendability". Kawasaki Steel Technical Report, Oct. 2000, No. 43, p. 55-57.

[13] Chen W., Peng Y., Wan C., Bao G., Tian Z.: "Welding thin plate of $400 \mathrm{MPa}$ grade ultra-fine grained steel using CO2 laser". Proc. of the Int. Symp. on Ultrafine Grained Steels (ISUGS 2001), Uminonakamichi, Fukuoka (Japan), September 20-22 2001, p. 252-255.

[14] Ito R., Shiga C., Kawaguchi Y., Nakamura,T., Hiraoka K., Hayashi T., Torizuka S.: "Controlling of the softened region in weld hyeat affected zone of ultra fine grained steels". ISIJ International, Vol. 40 (2000), p. S29-S33.

Jouko I. Leinonen, Ph.D. (Eng.)

phone: +358503250926

Fax: +35885532165

e-mail: Jouko.Leinonen@oulu.fi

Department of Mechanical Engineering

University of Oulu

Linnanmaa

FIN-90014 Oulu, Finland 